Intensity-dependent mortality of Paracalliope novizealandiae (Amphipoda: Crustacea) infected by a trematode: Experimental infections and field observations.

Fredensborg, Brian Lund; Mouritsen, Kim Nørgaard; Poulin, Robert

Published in:

Journal of Experimental Marine Biology and Ecology

Publication date:

2004

Citation for published version (APA):

Fredensborg, B. L., Mouritsen, K. N., \& Poulin, R. (2004). Intensity-dependent mortality of Paracalliope novizealandiae (Amphipoda: Crustacea) infected by a trematode: Experimental infections and field observations. Journal of Experimental Marine Biology and Ecology, 311. 


\title{
Intensity-dependent mortality of Paracalliope novizealandiae (Amphipoda: Crustacea) infected by a trematode: experimental infections and field observations
}

\author{
B.L. Fredensborg ${ }^{\mathrm{a}}$, K.N. Mouritsen ${ }^{\mathrm{b}}$, R. Poulin ${ }^{\mathrm{a}, *}$ \\ ${ }^{a}$ Department of Zoology, University of Otago, P.O. Box 56, Dunedin, New Zealand \\ ${ }^{\mathrm{b}}$ Department of Marine Ecology, Institute for Biological Sciences, Aarhus University, \\ Finlandsgade 14, DK-8200 Aarhus N, Denmark
}

Received 15 December 2003; received in revised form 6 May 2004; accepted 14 May 2004

\begin{abstract}
The impact of parasitism on population dynamics and community structure of marine animals is an area of growing interest in marine ecology. The effect of a microphallid trematode, Maritrema novaezelandensis on the survival of its amphipod host, Paracalliope novizealandiae, was investigated by a laboratory study combined with data from field collections. In the laboratory, the effect of infection level on host mortality was investigated. Four groups of individuals were exposed to 0 (control), 5 (low), 25 (moderate) and 125 (high) cercariae, respectively, and their survival was monitored during a 10-day period. The distribution and migration of unencysted cercariae within the host were examined during dissections 6 and $48 \mathrm{~h}$ post infection. Parasiteinduced mortality under field conditions was investigated by quantifying the relationship between parasite load and host body size. In the laboratory experiment, a highly significant decrease in host survival was observed for amphipods in the moderate and high infection groups relative to that of control amphipods. Parasite-induced mortality was most pronounced in the first two days post infection suggesting that the increased mortality is due to penetration of host cuticula and migration of cercariae within the host. Field data showed a monotonic increase in the mean parasite load with the body size of the amphipods, indicating that $M$. novaezelandensis does not severely affect $P$. novizealandiae-populations under normal field conditions. However, a decrease in the variance-tomean ratio for the largest size-classes indicates that heavily infected individuals are removed from the population as predicted by the experimental infections. The results from the laboratory study in conjunction with our knowledge of the transmission strategy of the parasite emphasize the potential
\end{abstract}

* Corresponding author. Tel.: +64-3-479-7983; fax: +64-3-479-7584.

E-mail address: robert.poulin@stonebow.otago.ac.nz (R. Poulin). 
effect of M. novaezelandensis on its amphipod host population during episodes of high temperature causing the rapid and massive release of cercariae from snail intermediate hosts.

(C) 2004 Elsevier B.V. All rights reserved.

Keywords: Amphipoda; Maritrema; Paracalliope; Parasite; Trematoda

\section{Introduction}

The importance of parasites in intertidal host ecology has received increasing attention from ecologists in recent years. Studies of parasites in their invertebrate hosts have often reported a significant impact on host survival, fecundity and growth (see Mouritsen and Poulin, 2002 and references therein). Furthermore, by affecting host species differently, parasites can mediate competitive interactions and predator-prey relationships (Minchella and Scott, 1991; Thomas et al., 1995c; Hudson and Greenman, 1998) and in turn affect the structure of the animal community and biodiversity in the intertidal ecosystem (Lauckner, 1987; Sousa, 1991; Poulin, 1999; Thomas et al., 1999; Mouritsen and Poulin, 2002). Yet, few studies have attempted to link parasite impacts measured in the laboratory with evidence from the field. A combination of the two methods is crucial in order to understand the impact of the parasite on its host population under normal field conditions, but also the potential effect of the parasite on host populations should optimal conditions for transmission occur.

Trematodes belonging to the family Microphallidae typically have a three-host life cycle, including crustaceans as second intermediate hosts. Free-living cercariae, released from the snail first intermediate host, penetrate the cuticula of a crustacean in which they encyst as metacercariae. The life cycle of the parasite is completed when the infected host is eaten by an appropriate definitive host, in most cases a shorebird. The proportion of intertidal crustaceans infected by microphallid trematodes in any given locality can occasionally reach high levels (Bick, 1994; Mouritsen et al., 1997, Meissner and Bick, 1997; Fredensborg, 2001; Meissner, 2001; Pung et al., 2002) and laboratory studies indicate that survival of infected individuals is generally negatively influenced by the parasite (Mouritsen and Jensen, 1997; Jensen et al., 1998; Meissner and Bick, 1999a,b). Direct measures of the survival of infected animals from field studies are, however, difficult to obtain and thus are rare in the ecological literature. Instead, indirect methods such as assessing the shape of the relationship between mean parasite load or variance-tomean ratio and host size-class are often used to infer parasite-induced mortality. The reasoning behind this is that if parasites accumulate in the host over time with no densitydependence, intensity-dependent host mortality will be detectable as a flattening of the infection intensity versus host size curve (Anderson and Gordon, 1982). The oldest and most heavily infected individuals will thus be removed from the population, leaving a convex relationship between both mean parasite load and variance-to-mean ratio and host size (Anderson and Gordon, 1982; Rousset et al., 1996). This method has been used once to demonstrate amphipod mortality induced by microphallid trematodes in the field (Thomas et al., 1995c). 
Recently, Maritrema novaezelandensis, a new microphallid trematode, has been described from the Otago Harbour, South Island, New Zealand. Its life cycle includes a snail first intermediate host (Zeacumantus subcarinatus), several species of amphipods and crabs as second intermediate hosts, and the red-billed gull (Larus hollandiiae scopulinus) as a definitive host (Martorelli et al., 2004). One of its amphipod hosts, Paracalliope novizealandiae (Dana, 1853), is an abundant and widespread species in the soft-bottom littoral zone, occupying beds of eelgrass (Zostera novaezelandensis) and patches of sea lettuce (Ulva lactuca), where it mainly feeds on epiphytic diatoms and fine detritus (Barnard, 1972; Cummings et al., 1995). Because of its abundance, it is believed to be an important component of the food web, serving as food for several fish species using the shallow intertidal areas as nursery grounds and for shorebirds.

In this study, direct measurements on the survival of $P$. novizealandiae in relation to intensity of infection by $M$. novaezelandensis were obtained from a laboratory experiment. Furthermore, mean parasite load and variance-to-mean ratio were estimated for fieldcollected amphipods to investigate whether infection intensity-dependent mortality occurs under field conditions. Possible pathological mechanisms involved in parasite-induced mortality and the potential impact of $M$. novaezelandensis on $P$. novizealandiae-population dynamics are discussed in relation to the results obtained and the transmission strategy of the parasite.

\section{Materials and methods}

\subsection{Field collections}

A large sample of amphipods was collected on two sampling occasions in late summer (March) and spring (October) 2003 from Lower Portobello Bay (LPB) and in March 2003 from Hoopers Inlet (HI) on the Otago Peninsula, South Island, New Zealand $\left(45^{\circ} 52^{\prime} \mathrm{S}\right.$, $170^{\circ} 42^{\prime} \mathrm{E}$ ). Both localities are intertidal (tidal range $=2 \mathrm{~m}$ ), and the sediment consists mainly of fine sand and mud. The two localities were selected based on the probability of finding Maritrema-infected amphipods known from earlier samples. In LPB the density of M. novaezelandensis-infected Z. subcarinatus is known to be relatively high and preliminary studies have confirmed the presence of Maritrema-infected amphipods at this locality (Fredensborg, unpublished data). In HI, on the other hand, the snail first intermediate host is absent and amphipods are therefore not expected to harbour any $M$. novaezelandensis metacercariae.

Amphipods were randomly sampled during low tide from shallow pools $(5 \mathrm{~cm}$ deep) 50 $\mathrm{m}$ from MHWL. The pools are isolated during low tide (10-12 h per day) and contain eelgrass (Z. novaezelandensis) and sea lettuce (U. lactuca). A plankton-net was dragged through the water and the animals captured were transferred to a plastic container $(25 \times 15 \times 15 \mathrm{~cm})$ half-filled with seawater.

In addition, in LPB, a large sample of $Z$. subcarinatus snails was collected by hand from the same tidal pools, stored in a separate container and returned to the laboratory for use in the experiments described below. 


\subsection{Field study}

For each of the sampling occasions, approximately 300 amphipods from LPB were randomly taken from the field-collected samples, measured (rostrum to telson), sexed and the number of parasites they harboured counted. Extra amphipods were selected to ensure that all available size classes were represented in the data set. Cercariae and metacercariae of M. novaezelandensis were identified according to Martorelli et al. (2004). No other species of parasites were found in these amphipods. In addition, for egg-bearing female amphipods, the number of eggs in the brooding pouch was recorded.

The amphipods were divided into 8 size-classes. Group 1-individuals included all specimens smaller than $2.0 \mathrm{~mm}$ which corresponds to the approximate size of sex determination in $P$. novazealandiae. Size classes $2-7$ are of equal length intervals $(0.5$ $\mathrm{mm}$ ) and contain individuals ranging from 2.0 to $5.0 \mathrm{~mm}$. Size class 8 includes all individuals longer than $5.0 \mathrm{~mm}$.

\subsection{Experimental infections}

Fifty randomly chosen amphipods from HI were dissected to confirm that $M$. novaezelandensis was not present and to check for the presence of any other parasites. All amphipods examined were uninfected and individuals from this locality were therefore used in the subsequent experimental infections.

A total of 400 amphipods from HI was then divided randomly and evenly into three treatment groups and a control group and transferred individually to $5 \mathrm{ml}$ containers. The four groups were exposed to 0 (control), 5 (low), 25 (moderate) and 125 (high) $M$. novaezelandensis-cercariae. Thirty infected $Z$. subcarinatus snails were placed individually in $10 \mathrm{ml}$ plastic dishes and incubated at $25{ }^{\circ} \mathrm{C}$ for 30 min under constant illumination to facilitate cercarial emergence. Cercariae were transferred to the amphipod holding containers using a 200- $\mu$ l Eppendorf pipette. The volume of water was then adjusted to 0.5 $\mathrm{ml}$ and the containers from all four groups were incubated at $25{ }^{\circ} \mathrm{C}$ under constant illumination for $6 \mathrm{~h}$ to ensure optimal conditions for transmission. Amphipods in the control group were incubated under the same conditions to take into account any mortality related to the incubation process. To ensure an equal age and thus equal infectivity of cercariae, amphipods from the three infection treatments were infected in random order. A second batch of snails was incubated $2 \mathrm{~h}$ later than the first one to avoid differences in infectivity between cercariae used early and late in the infection process. After $6 \mathrm{~h}$ of incubation, dead amphipods were removed for examination of parasite intensity. The remaining containers were filled with seawater $(5 \mathrm{ml})$, supplied with a strip of sea lettuce (U. lactuca), and stored at $18 \pm 2{ }^{\circ} \mathrm{C}$ and at the natural photoperiod (12 h light:12 h dark). Amphipod survival was checked three times per day and the water level adjusted daily. Dead amphipods were measured, sexed and the number of parasites they harboured was counted. As the parasites decompose very quickly after the death of the host, only parasites from amphipods dying during the day could be recovered.

Another 20 amphipods were divided in two groups of ten and individually exposed to 25 cercariae each using the method described above. The two groups were dissected at 6 and $48 \mathrm{~h}$ post infection, respectively, to check for site of infection and migration of 




Fig. 1. Illustration of $P$. novizealandiae with indications of the division of the amphipod into the parts used in the migration experiment. $\mathrm{h}=$ head, $\mathrm{u}=$ urosome. See text for further details.

cercariae within the host. Because of the small body size of $P$. novizealandiae (maximum length of $5.5 \mathrm{~mm}$ ), it was impractical to dissect each body segment separately and each amphipod's body was therefore divided into six parts as indicated in Fig. 1.

Statistical analyses were performed using the statistical packages SPSS for Windows (10.1) and Statistica (6.0). All tests were two-tailed and used the 5\% level of significance.

\section{Results}

\subsection{Field study}

Amphipods collected in October attained larger sizes than amphipods collected in March (Fig. 2). The largest size-classes in October belong to an over-wintering generation from the previous reproductive season that dies out during the summer whereas the small individuals collected in March belong to two summer generations produced in spring and early summer. Overall, prevalence of infection by $M$. novaezelandensis in the March sample was $65.3 \%$, with number of metacercariae per infected amphipod ranging from 1 to 24 ; in the October sample, prevalence was $56.1 \%$ and the range was $1-16$.

The proportion of $P$. novizealandiae infected with $M$. novaezelandensis and the mean number of metacercariae per host did not differ between females and males of the same size class within the two sampling occasions (Yates corrected Chi-square test and MannWhitney test, respectively, $p>0.05$ for all pair-wise comparisons), and parasite data for the two sexes were thus pooled for subsequent analysis. Parasite prevalence increased with size-class on both sampling occasions (Fig. 2a). However, for size-classes 2-4 the prevalence was significantly higher in individuals sampled in March compared with the October sample (Yates corrected Chi-square test, $p<0.05$ for all pair-wise comparisons).

Mean parasite load increased with host size (Fig. 2b) on both sampling occasions and as with the prevalence data, amphipods in size classes 2-4 collected in March harboured significantly more metacercariae than individuals of the same size sampled in October (Mann-Whitney test, $p<0.05$ for all pair-wise comparisons). The relationship between size-class and variance-to-mean ratio showed a very similar pattern between the two 

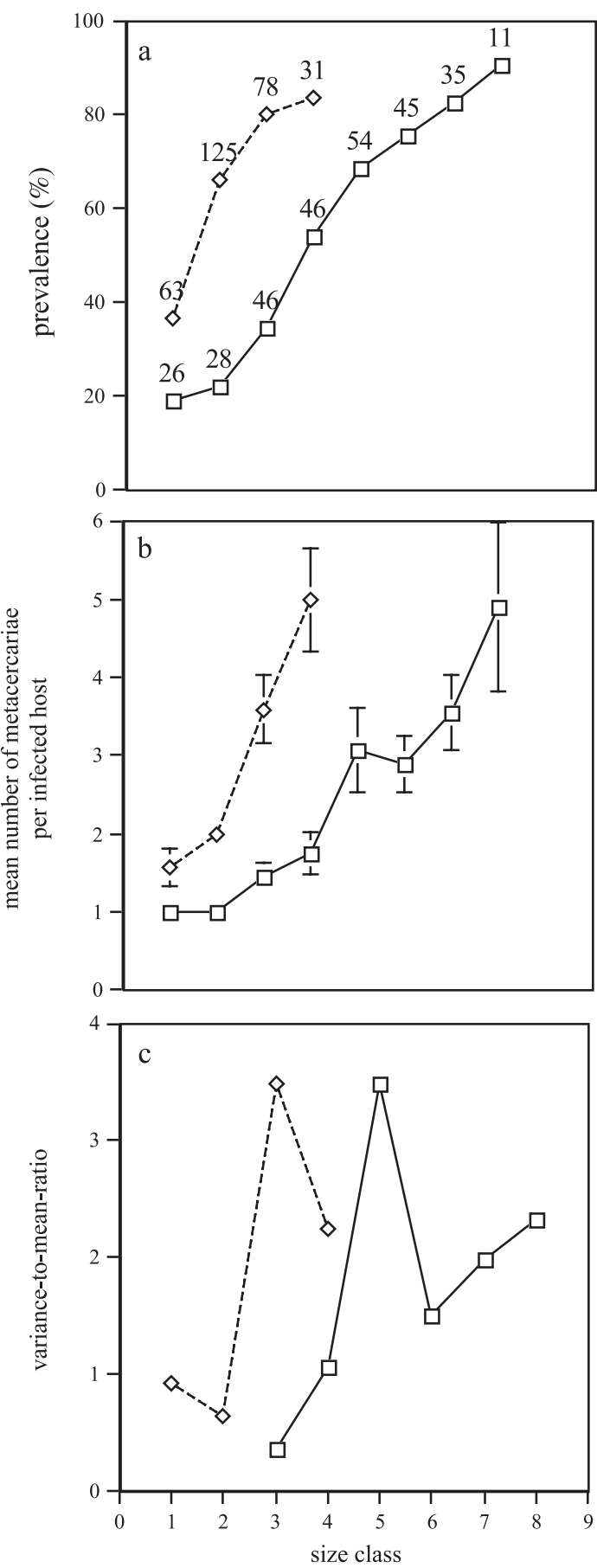
samples (Fig. 2c). A low variance-to-mean ratio in the smallest size-classes was followed by a sharp increase for larger individuals with a subsequent decrease for the largest specimens in the population. The variance in the number of parasites per host was thus lower for the largest size-classes compared to medium-sized individuals.

In March, 79 female amphipods were examined, of which 38 harboured one or more eggs in the brood pouch. The number of eggs was not significantly correlated with female size on this sampling occasion $\left(r_{\mathrm{s}}=0.15, p=0.36\right)$ and mean number of eggs did not differ between infected $(4.35 \pm 0.43)$ and uninfected $(4.42 \pm 0.60)$ females (mean \pm S.E.) (Mann-Whitney test, $p=0.99)$. In October, 49 females out of 63 examined were ovigerous. The number of eggs was significantly correlated with size of the female $\left(r_{\mathrm{s}}=0.75, p<0.001\right)$. However, residuals of the correlation between female size and number of eggs were not correlated with parasite intensity in the female $\left(r_{\mathrm{s}}=-0.09\right.$, $p=0.54$ ). Furthermore, the proportion of non-ovigerous females did not differ between infected and uninfected females on any of the sampling occasions (Yates corrected Chisquare test, $\chi_{1}^{2}=0.05, p=0.82$, and $\chi^{2}{ }_{1}=1.04, p=0.31$ in March and October, respectively).

\subsection{Experimental infections}

The mean intensity of infection for each treatment group was determined by dissections of recently dead amphipods collected daily during the experiment (Fig. 3). A KruskalWallis test revealed a highly significant difference in the number of parasites per amphipod between the three treatments $\left(\chi_{2}^{2}=76.57, p<0.001\right)$. Posthoc multiple comparisons between treatments were carried out as recommended by Siegel and Castellan (1988), and showed a significant difference in the mean number of parasites per amphipod between all three groups ( $p<0.05$ for all pair-wise comparisons).

The survival curves for the four treatments are shown in Fig. 4. There was a highly significant effect of treatment on amphipod survival. A highly significant difference was observed in the survival rate between the control group and the moderate infection group (Kolmogorov-Smirnov two-sample test, $n_{\text {control }}=76, n_{\text {moderate }}=97, p<0.001$ ) and also between the moderate and high infection groups $\left(n_{\text {moderate }}=97, n_{\text {high }}=45, p<0.001\right)$. There was, however, no difference between the control group and the low infection group $\left(n_{\text {control }}=76, n_{\text {low }}=87, p=0.83\right)$. The difference between the survival curves was mainly due to a high mortality of moderate and highly infected hosts in the first two days post infection (p.i.) (Fig. 4). Later in the experiment, however, the remaining individuals from the high infection group had a higher survival rate than individuals in the control group (from day 2 p.i. onwards, test of homogeneity of slopes of regression lines, $F=69.40$, $p<0.001$ ).

Fig. 2. Infection parameters of $M$. novaezelandensis for each of eight size-classes of $P$. novizealandiae collected from Lower Portobello Bay, Otago Peninsula on two occasions. The dotted line denotes individuals collected in March 2003 whereas the solid line denotes individuals collected in October 2003. (a) Prevalence of infection, i.e. percentage of amphipods in each size-class infected with M. novaezelandensis. (b) Mean parasite load per sizeclass ( \pm S.E.). (c) Variance-to-mean ratio in numbers of parasites per amphipod, per size-class. Sample sizes are indicated above each point in (a). 




Fig. 3. Mean intensity of parasites per host $( \pm$ S.E. $)$ in amphipods exposed individually to three levels of M. novaezelandensis-cercariae: 5 cercariae (low), 25 cercariae (moderate) or 125 cercariae (high). Sample sizes are indicated above each bar.

Dissection of amphipods 6 and $48 \mathrm{~h}$ post infection showed that the distribution of parasites within the host is significantly different between these two times (Fig. 5) (Chisquare test, $\chi_{5}^{2}=42.84, p<0.001$ ). Unencysted cercariae were found in all body parts at both dissection times. However, after $48 \mathrm{~h}$ the cercariae were more concentrated in parts 2

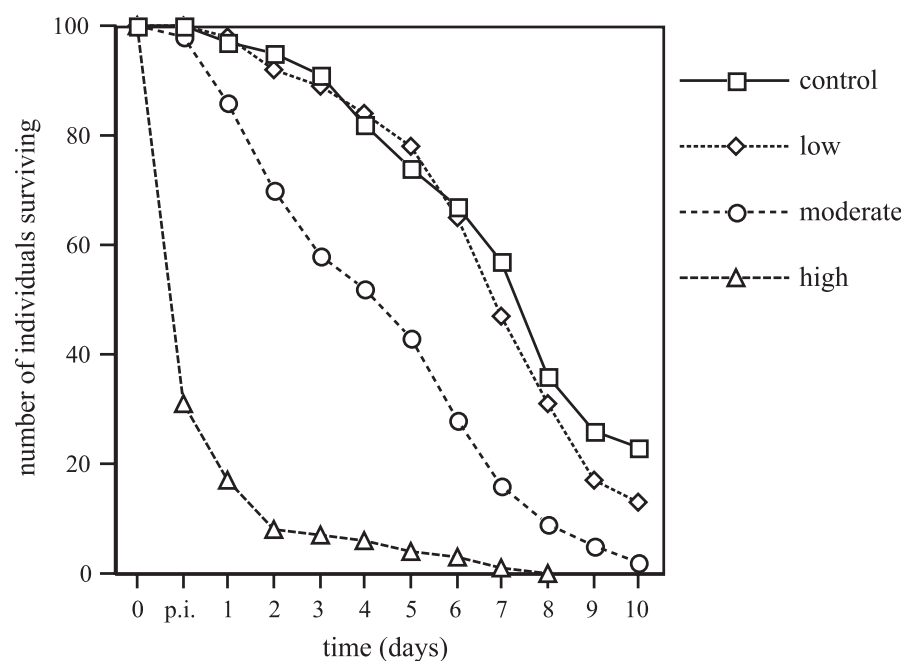

Fig. 4. Number of surviving amphipods over time for each of four levels of exposure to M. novaezelandensiscercariae: Control (unexposed), low (5 cercariae), moderate (25 cercariae) and high (125 cercariae). The notation p.i. marks the end of the 6-h incubation period. 


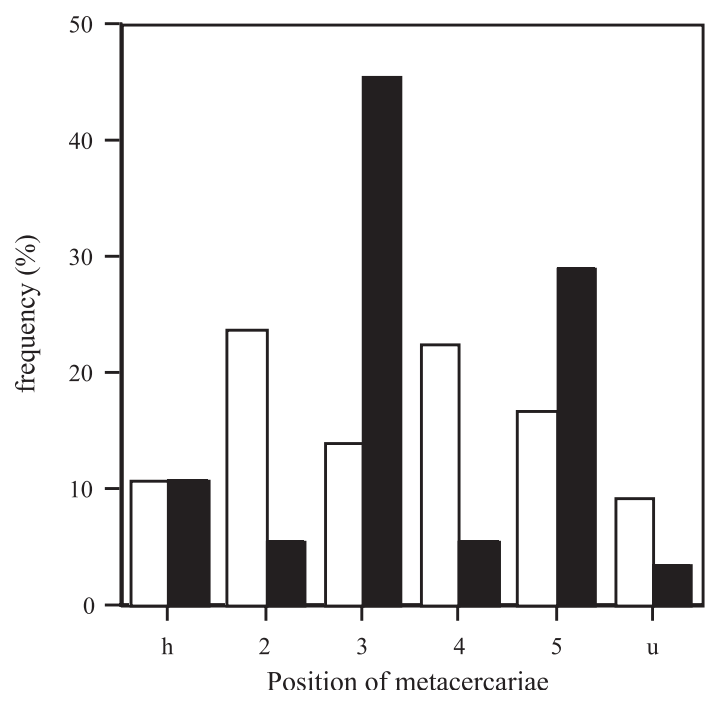

Fig. 5. Frequency distribution of $M$. novaezelandensis-cercariae, all not yet encysted, in different body parts of the amphipod host at $6 \mathrm{~h}$ post infection (white bars) ( $n=8$ amphipods, 248 cercariae), and $48 \mathrm{~h}$ post infection (black bars) ( $n=9$ amphipods, 55 cercariae). The division of body parts is indicated in Fig. 1.

and 4 (pereion and the pleon, respectively) showing that migration of unencysted metacercariae takes place within the host in the first 1-2 days after infection.

\section{Discussion}

From the experimental infections it is clear that the effect of the parasite on amphipod survival is intensity dependent (Fig. 4). A small number of cercariae does not affect the survival of the amphipod host while a moderate or high number of parasites highly decreases host survival. The pathological effects of trematode cercariae on amphipod hosts are not very well known. However, based on development of microphallid metacercariae and studies of their effects on amphipod hosts, the impact of infection can be divided into four temporally separate stages: (1) Penetration of the amphipod host cuticula by the cercariae. (2) Migration of mesocercariae within host tissue. (3) Growth phase of the metacercariae. (4) The fully developed metacercarial stage. Whereas the first three stages represent an active influence of the parasite on host physiology, the fourth is a developmentally inactive stage, where the mature parasite awaits transmission to the definitive bird host (Galaktionov et al., 1996, 1997). The mere presence of metacercariae in the host, however, may cause pathology.

Penetration holes in host cuticula may cause loss of haemolymph leading to acute anaemia and osmotic stress, as well as giving rise to secondary infections by microorganisms (Meyer, 1990; Mouritsen and Jensen, 1997; Jensen et al., 1998). Assuming that loss of haemolymph is positively correlated with the number of penetration holes, the effect on the amphipod host is expected to be intensity dependent. The very high mortality 
of highly infected amphipods early in the infection process confirms that multiple penetrations of the cuticula significantly and rapidly decrease host survival.

After successful penetration, microphallid trematodes migrate within their second intermediate host for a period of a few hours to a few days before encystation begins (Galaktionov et al., 1996). This stage is believed to have a destructive impact on host organs and connective tissue (Meissner and Bick, 1999a). As indicated in Fig. 4b, migration of $M$. novaezelandensis-mesocercariae does take place in the first day or two of infection, and it is likely to be a factor in the observed increase in host mortality. Unlike most other trematodes, microphallids undergo large developmental changes in the second intermediate host, which implies occupation of space and absorption of nutrients from the host. The increment in volume from the cercarial stage to a fully developed metacercaria is about two-hundred-fold for M. novaezelandensis which is unusually high compared to other trematodes (Poulin and Latham, 2003). Such an increase in size is likely to affect the space available for host organs and perhaps the flow of haemolymph, whereas the effect of the nutritional demands of the parasite is unknown. The laboratory experiment only includes the first ten days of infection and the full extent of the effect of parasite growth on host survival has therefore not been investigated. The mortality of amphipods seems, however, to be less pronounced from day two to day 10 in spite of an observed increment in the size of metacercariae during that period.

After the development of a metacercaria is completed there is no absorption of nutrients across the cyst wall and any physical effect of the parasite on the host is due solely to the presence of the cyst. Other studies have reported a much less significant pathological effect of encysted metacercariae on amphipod hosts (Jensen et al., 1998; Thomas et al., 1998; Meissner and Bick, 1999a; Meissner and Schaarschmidt, 2000).

The difference in both prevalence and mean intensity of metacercariae between the two sampling occasions is believed to be due to a difference in the time of exposure to parasites. In October the temperature has only recently allowed cercarial transmission from snail to amphipods, while amphipods in March, despite their younger age, have been exposed to the parasite for a longer time during summer. The monotonic increase in mean parasite load with host body length in two field sampling occasions suggest that cysts accumulate throughout the lifetime of the amphipod host without affecting host survival. The decrease in variance-to-mean ratio observed in the largest individuals on both sampling occasions does, however, suggest that lethal levels of infection are occasionally reached. Both of these results are consistent with our laboratory study in which we showed that low levels of new infections do not alter host survival whereas survival is significantly reduced when the host is challenged by a higher number of infections.

Knowing the importance of the initial infection challenge to host mortality, the potential effect of $M$. novazelandensis on Paracalliope populations is thus dependent on the transmission strategy of the parasite. Release of trematode cercariae from the snail host and successful transmission to the amphipod host is highly temperature-dependent (e.g. Mouritsen and Jensen, 1997; Mouritsen, 2002). Accordingly, a previous study on $M$. novaezelandensis reported that cercarial emergence from $Z$. subcarinatus increases threefold when the temperature rises from 19 to $25{ }^{\circ} \mathrm{C}$ (from 80 to 250 cercariae per snail per day) (B. Fredensborg, K.N. Mouritsen and R. Poulin, unpublished data). In summer, the temperature frequently reaches $25{ }^{\circ} \mathrm{C}$ or more in shallow tidal pools in the study area 
(personal observation). With densities of Maritrema-infected snails reaching 152 ind. $\mathrm{m}^{-2}$ in some localities, a burst of cercariae will be released during warm sunny days, increasing the risk of simultaneous multiple infections in the amphipods. Bearing in mind that even a moderate infection rate significantly increases host mortality in the first 2 days postinfection, it seems reasonable to assume that $M$. novaezelandensis occasionally induces severe host mortality under field conditions.

Whether parasite-induced mortality is truly additive or more of a compensatory nature has been a matter of debate. That is, if parasites remove individuals from the population that would have died otherwise from different causes, then the effect of parasite-induced mortality will often remain undetected in host populations (see Holmes, 1982). It is interesting to note that individuals in the high infection group had a higher survival rate than the control group after day 2 post-infection (judged by the slope of the mortality rate in Fig. 4). The observed pattern suggests the existence of variation in vulnerability between individuals from the same population, and that parasite-induced mortality at least to some extent may be compensatory rather than additive. If that applies to field conditions, M. novaezelandensis may not exert any significant influence on host population dynamics even though it induces an increase in host mortality. Under normal weather conditions, $M$. novaezelandensis is thus not expected to have a regulatory effect on $P$. novizealandiae-populations. Exceptional situations of prolonged periods of warm weather may, however, trigger a massive infection event in localities where infected snail densities are high, leading to profound and rapid reductions in amphipod populations as observed in other microphallidamphipod systems (Muus, 1967; Jensen and Mouritsen, 1992). Under such circumstances, the effect of the parasite could possibly extend beyond the host population by affecting the food available for its predators. Future studies will need to address specifically the matter of additive versus compensatory mortality implied from the laboratory study.

Production of eggs in amphipods is often closely related to female body size (Thomas et al., 1995b, 1996), as we observed in our October sample. Some parasites are known to significantly decrease fecundity in their crustacean hosts (Reinhard, 1956; Shields and Wood, 1993; Bollache et al., 2002) and microphallid trematodes have previously been reported to have a negative impact on female egg-production in amphipods (Thomas et al., 1995a,b). However, in this study no influence of infection status or parasite load could be detected on female egg-production on any of the two sampling occasions.

In conclusion, often the impact of parasites observed in the laboratory is merely assumed to extend to field situations. In this study, we show that a pronounced mortality induced by trematodes in the laboratory is likely to be more subtle under natural conditions. The transmission strategy of M. novaezelandensis does, however, suggest that the parasite can have, occasionally, severe impacts on its amphipod host population.

\section{Acknowledgements}

This study was funded by a grant from the Marsden Fund to R. Poulin and a grant from the Danish Natural Science Research Council to K.N. Mouritsen. We wish to thank 
Graham Fenwick for his help with identification of the amphipod species and Francois Lefebvre for useful comments on an earlier draft.

\section{References}

Anderson, R.M., Gordon, D.M., 1982. Processes influencing the distribution of parasite numbers within host populations with special emphasis on parasite-induced host mortalities. Parasitology 85, 373-398.

Barnard, J.L., 1972. The marine fauna of New Zealand: algae living littoral Gammaridea (Crustacea Amphipoda). Memoir of the New Zealand Oceanographic Institute no.62.

Bick, A., 1994. Corophium volutator (Corophiidae: Amphipoda) as an intermediate host of larval Digenea-an ecological analysis in a coastal region of the southern Baltic. Ophelia 40, 27-36.

Bollache, L., Rigaud, T., Cezilly, F., 2002. Effects of two acanthocephalan parasites on the fecundity and pairing status of female Gammarus pulex (Crustacea: Amphipoda). J. Invertebr. Pathol. 79, 102-110.

Cummings, V.J., Pridmore, R.D., Thrush, S.F., Hewitt, J.E., 1995. Post-settlement movement by intertidal benthic macroinvertebrates: do common New Zealand species drift in the water coloumn? N.Z. J. Mar. Freshw. Res. 29, 59-67.

Fredensborg, B.L., 2001. Dynamics of microphallid trematodes in the intermediate hosts Hydrobia ulvae and Corophium volutator during autumn. M.Sc. thesis, Institute of Biology, Department of Marine Ecology, University of Aarhus, Denmark.

Galaktionov, K.V., Malkova, I.I., Irwin, S.W.B., Saville, D.H., Maguire, J.G., 1996. Developmental changes in the tegument of four microphallid metacercariae in their second (crustacean) intermediate hosts. J. Helminthol. $70,201-210$.

Galaktionov, K.V., Malkova, I.I., Irwin, S.W.B., Saville, D.H., Maguire, J.G., 1997. The structure and formation of metacercarial cysts in the trematode family Microphallidae Travassos 1920. J. Helminthol. 71, 13-20.

Holmes, J.C., 1982. Impacts on infectious disease agents on the population growth and geographical distribution of animals. In: Anderson, R.M., May, R.M. (Eds.), Population Biology of Infectious Diseases, Dahlem Konferenzen 1982. Springer Verlag, Berlin, pp. 37-51.

Hudson, P., Greenman, J., 1998. Competition mediated by parasites: biological and theoretical progress. Trends Ecol. Evol. 13, 387-390.

Jensen, K.T., Mouritsen, K.N., 1992. Mass mortality in two common soft-bottom invertebrates, Hydrobia ulvae and Corophium volutator - the possible role of trematodes. Helgol. Meeresunters. 46, 329-339.

Jensen, T., Jensen, K.T., Mouritsen, K.N., 1998. The influence of the trematode Microphallus claviformis on two congeneric intermediate host species (Corophium): infection characteristics and host survival. J. Exp. Mar. Biol. Ecol. 227, 35-48.

Lauckner, G., 1987. Ecological effects of larval trematode infestations on littoral marine invertebrate populations. Int. J. Parasitol. 17, 391-398.

Martorelli, S., Fredensborg, B.L., Mouritsen, K.N., Poulin, R., 2004. Description and proposed life cycle of Maritrema novaezelandensis n. sp. (Microphallidae) parasitic in red-billed gulls Larus novaehollandiae scopulinus from Otago Harbor, South Island, New Zealand. J. Parasitol. 90, 272-277.

Meissner, K., 2001. Infestation patterns of microphallid trematodes in Corophium volutator (Amphipoda). J. Sea Res. $45,141-151$.

Meissner, K., Bick, A., 1997. Population dynamics and ecoparasitological surveys of Corophium volutator in coastal waters in the Bay of Mecklenburg (southern Baltic Sea). Dis. Aquat. Org. 29, 169-179.

Meissner, K., Bick, A., 1999a. Mortality of Corophium volutator (Amphipoda) caused by infestation with Maritrema subdolum (Digenea, Microphallidae)—laboratory studies. Dis. Aquat. Org. 35, 47-52.

Meissner, K., Bick, A., 1999b. Laboratory studies of parasite transmission aspects between Hydrobia spp. (Gastropoda) and Corophium volutator (Amphipoda). Int. Rev. Hydrobiol. 84, 61-72.

Meissner, K., Schaarschmidt, T., 2000. Ecophysiological studies of Corophium volutator (Amphipoda) infested by microphallid trematodes. Mar. Ecol., Prog. Ser. 202, 143-151.

Meyer, T.R., 1990. Diseases caused by protistans and metazoans. In: Kinne, O. (Ed.), Diseases of Marine Animals, vol. 3. Biologische Anstalt Helgoland, Hamburg, pp. 350-423. 
Minchella, D.J., Scott, M.E., 1991. Parasitism: a cryptic determinant of animal community structure. Trends Ecol. Evol. 6, 250-253.

Mouritsen, K.N., 2002. The Hydrobia ulvae-Maritrema subdolum association: influence of temperature, salinity, light, water-pressure and secondary host exudates on cercarial emergence and longevity. J. Helminthol. 76, $341-347$.

Mouritsen, K.N., Jensen, K.T., 1997. Parasite transmission between soft-bottom invertebrates: temperature mediated infection rates and mortality in Corophium volutator. Mar. Ecol., Prog. Ser. 151, 123-134.

Mouritsen, K.N., Poulin, R., 2002. Parasitism, community structure and biodiversity in intertidal ecosystems. Parasitology 124, S101-S117.

Mouritsen, K.N., Jensen, T., Jensen, K.T., 1997. Parasites on an intertidal Corophium-bed: factors determining the phenology of microphallid trematodes in the intermediate host populations of the mud-snail Hydrobia ulvae and the amphipod Corophium volutator. Hydrobiologia 355, 61-70.

Muus, B., 1967. The fauna of Danish estuaries and lagoons. Distribution and ecology of dominating species in the shallow reaches of the mesohaline zone. Medd. Komm. Dan. Fisk. Havunders., Ser. Fisk. 5, 1-316.

Poulin, R., 1999. The functional importance of parasites in animal communities: many roles at many levels? Int. J. Parasitol. 29, 903-914.

Poulin, R., Latham, A.D.M., 2003. Effects of initial (larval) size and host body temperature on growth in trematodes. Can. J. Zool. 81, 574-581.

Pung, O.J., Khan, R.N., Vives, S.P., Walker, C.B., 2002. Prevalence, geographic distribution, and fitness effects of Microphallus turgidus (Trematoda: Microphallidae) in grass shrimp (Palaemonetes spp.) from coastal Georgia. J. Parasitol. 88, 89-92.

Reinhard, E.G., 1956. Parasitic castration of Crustacea. Exp. Parasitol. 5, 79-107.

Rousset, F., Thomas, F., De Meeus, T., Renaud, F., 1996. Inference of parasite-induced host mortality from distributions of parasite loads. Ecology 77, 2203-2211.

Shields, J.D., Wood, F.E.I., 1993. Impact of parasites on the reproduction and fecundity of the blue sand crab Portunus pelagicus from Moreton Bay, Australia. Mar. Ecol. Prog.Ser. 92, 159-170.

Siegel, S., Castellan, N.J., 1988. Nonparametric Statistics for the Behavioural Sciences, 2nd ed. McGraw-Hill, New York.

Sousa, W., 1991. Can models of soft-sediment community structure be complete without parasites? Am. Zool. 31, $821-830$

Thomas, F., Lambert, A., De Meeüs, T., Cézilly, F., Renaud, F., 1995a. Influence of Microphallus hoffmani (Trematoda, Microphallidae) on the survival, sexual selection and fecundity of Gammarus aequicauda (Amphipoda). Can. J. Zool. 73, 1634-1639.

Thomas, F., Renaud, F., Derothe, J.M., Lambert, A., De Meeüs, T., Cézilly, F., 1995b. Assortative pairing in Gammarus insensibilis (Amphipoda) infected by a trematode parasite. Oecologia 104, 259-264.

Thomas, F., Renaud, F., Rousset, F., Cézilly, F., De Meeüs, T., 1995c. Differential mortality of two closely related host species induced by one parasite. Proc. R. Soc. Lond., B 260, 349-352.

Thomas, F., Verneau, O., Santalla, F., Cézilly, F., Renaud, F., 1996. The influence of intensity of infection by a trematode parasite on the reproductive biology of Gammarus insensibilis (Amphipoda). Int. J. Parasitol. 26, $1205-1209$.

Thomas, F., Villa, M., Montoliu, I., Santalla, F., Cézilly, F., Renaud, F., 1998. Analyses of a debilitating parasite (Microphallus papillorobustus, Trematoda) and its "hitchhiker" parasite (Maritrema subdolum, Trematoda) on survival of their intermediate host (Gammarus insensibilis, Amphipoda). J. Helminthol. Soc. Wash. 65, 1-5.

Thomas, F., Poulin, R., de Meeüs, T., Guegan, J.-F., Renaud, F., 1999. Parasites and ecosystem engineering: what roles could they play? Oikos $84,167-171$. 